atrium. The pathologic diagnosis of the aneurysm was atherosclerotic and the follow-up CT scan showed normal atria and venae cavae. The postoperative course was uneventful and the patient was discharged on the twelfth postoperative day.

Coronary artery aneurysm is a relatively rare disease, with the incidence being reported to be $0.3 \%$ to $4.9 \%$ of patients undergoing coronary angiography. ${ }^{1}$ The most common sites of aneurysm are the proximal and middle portions of the RCA, followed by the proximal left anterior descending artery ${ }^{2}$; however, an aneurysm of the SA nodal branch of the RCA has not previously been reported. RCA aneurysm may cause angina, myocardial infarction, fistula into the cardiac chamber, and unexpected death as a result of thromboembolism or rupture. ${ }^{1,3}$ Ovrum, Froysaker, and Vatne ${ }^{4}$ reported a single case of RCA aneurysm causing superior vena caval stenosis in 1984. Our case involved both caval obstructive symptoms without any of the aforementioned clinical features.

In our case, the abnormally dilated SA nodal artery branched from the normal-sized RCA, $5 \mathrm{~mm}$ apart from the aorta. It ran behind the superior cavoatrial junction for about $2.5 \mathrm{~cm}$ and finally formed the giant aneurysm. Preoperative and postoperative electrocardiograms did not show any abnormality, and we could not confirm the SA nodal branch from the left coronary arterial system by angiography. Thus we concluded that it was indeed an aneurysm of the SA nodal artery as a result of the path it followed.

\section{REFERENCES}

1. Eid GA, Lang-Lazdunski L, Hvass U, et al. Management of giant coronary artery aneurysm with fistulization into the right atrium. Ann Thorac Surg 1993;56:372-4.

2. Swaye PS, Fisher LD, Litwin P, et al. Aneurysmal coronary artery disease. Circulation 1983;67:134.

3. Koito R, Oku T, Satoh H, et al. Right ventricular myocardial infarction and late cardiac tamponade due to right coronary artery aneurysm: a case report. Jpn J Surg 1990;20:463-7.

4. Ovrum E, Froysaker T, Vatne K. Superior caval vein stenosis due to giant aneurysm of the right coronary artery. Thorac Cardiovasc Surg 1984;32:383-5.

\title{
TOTAL ANOMALOUS SYSTEMIC VENOUS DRAINAGE TO THE CORONARY SINUS IN ASSOCIATION WITH HYPOPLASTIC LEFT HEART DISEASE: MORE THAN A MERE COINCIDENCE
}

Margit Kadletz, MD, ${ }^{a}$ Michael D. Black, MD, ${ }^{a}$ Jeffery Smallhorn, MD, ${ }^{\mathrm{b}}$ Robert M. Freedom, MD, ${ }^{\mathrm{b}}$ and Stella Van Praagh, MD, ${ }^{c}$ Toronto, Ontario, Canada, and Boston, Mass.

An enlarged coronary sinus receiving a persistent left superior vena cava (SVC) has been considered to accentuate the left-to-right shunt in cases of ostium secundum defects by obstructing left ventricular inflow. ${ }^{1}$ An ostium primum defect could also be considered a factor in deficient preload to the left ventricle because it represents a valveless interatrial communication that can allow bidirectional shunting at the atrial level during fetal life. Underdevelopment of the left atrium, the left ventricle, and the mitral valve, usually associated with coarctation of

From the Divisions of Cardiovascular Surgery ${ }^{\mathrm{a}}$ and Cardiology, ${ }^{\mathrm{b}}$ The Hospital for Sick Children, and The University of Toronto Faculty of Medicine, Toronto, and the Department of Pathology, Children's Hospital, Boston, Mass. ${ }^{\mathrm{c}}$

Received for publication Nov. 21, 1996; accepted for publication Dec. 23, 1996.

Address for reprints: Michael D. Black, MD, FRCSC, Division of Cardiovascular Surgery, The Hospital for Sick Children, 555 University Ave., Toronto, Canada, M5G 1X8.

J Thorac Cardiovasc Surg 1997;114:282-4

Copyright $(0) 1997$ by Mosby-Year Book, Inc.

$0022-5223 / 97 \$ 5.00+0 \quad \mathbf{1 2 / 5 4 / 8 0 0 3 4}$ the aorta, is not uncommon in patients with ostium primum defects who show signs of heart failure in early infancy. $^{2}$ Our case represents an example of coexistence of these factors that may influence the blood flow into the left ventricle during fetal life.

Clinical summary. A 3-month-old, $3.5 \mathrm{~kg}$ female infant was transferred to the Hospital for Sick Children in Toronto for a second opinion regarding further management and treatment options for a preliminary diagnosis of hypoplastic left heart syndrome. In agreement with the previous investigations, hypoplasia of the inlet, outlet, and decreased volumetrics of the left ventricle were identified. A diagnosis of hypoplastic left ventricle, however, was not made. The left ventricle was estimated to be approximately $70 \%$ normal and was found in combination with a hypoplastic "parachute" mitral valve, a partial atrioventricular septal defect (ostium primum defect), an ostium secundum atrial septal defect, a hypoplastic aorta (transverse arch) with an associated juxtaductal coarctation, and a bicuspid aortic valve. In addition, significant tricuspid valve regurgitation and a left-to-right atrial shunt were present at the time of the investigations.

Preoperative identification of an absent right SVC and a persistent left SVC was made angiographically (Fig. 1). 


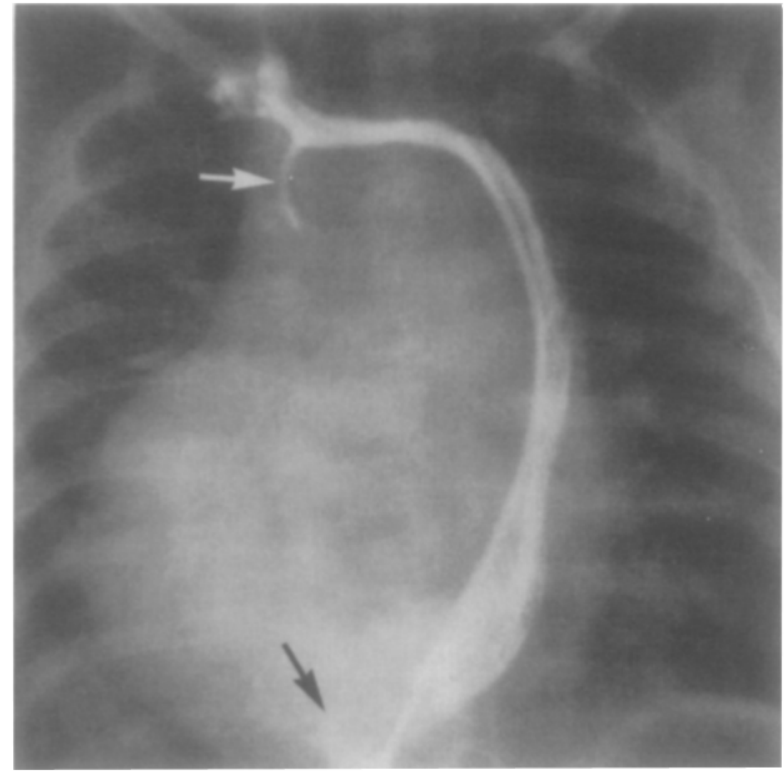

Fig. 1. Angiography demonstrates catheter insertion through IVC passing ostium of coronary sinus, persistent left SVC, and left innominate vein en route to atretic right SVC. Dye demonstrates direct communication of venae cavae with coronary sinus. Black arrow, Ostium of coronary sinus; white arrow, atretic remnant of right SVC.

No morphologic abnormalities of the inferior vena cava (IVC) were identified below the level of the diaphragm (i.e., the IVC remained right sided with normal hepatic venous drainage; Fig. $2, A$ ). The intraoperative finding of abnormal drainage of the IVC into the coronary sinus was confirmed by reviewing the previously performed investigations (Fig. 1 and Fig. 2, B).

To avoid circulatory arrest, the surgical procedure combined a left thoracotomy (coarctation repair) with a median sternotomy (intracardiac repair). Moderate hypothermia and low systemic flows were used during cardiopulmonary bypass. On pericardiotomy, the right ventricle was found to be anterior and extremely rightward, composing the border of the right side of the heart. The right atrium was not visible, except for the tip of the right atrial appendage. The appendages were not juxtaposed or isomeric. Venous return was achieved by cannulation of the left SVC and right atrial appendage, with eventual conversion of the latter site to the IVC. There was some difficulty in placing the IVC cannula. The IVC was found in a midline position, with a normal-appearing hepatic venous drainage pattern. After cardioplegic infusion, the caval snares were tightened and a right atriotomy was made.

There were two separate atrioventricular valves. The tricuspid valve was difficult to see because it was extremely anterior. It contained accessory valvular tissue, which was excised in concert with a commissuroplasty. The ostium of the coronary sinus was found to be impressively large. The IVC cannula was now seen within the ostium of the coronary sinus, providing an explanation of the cannula's
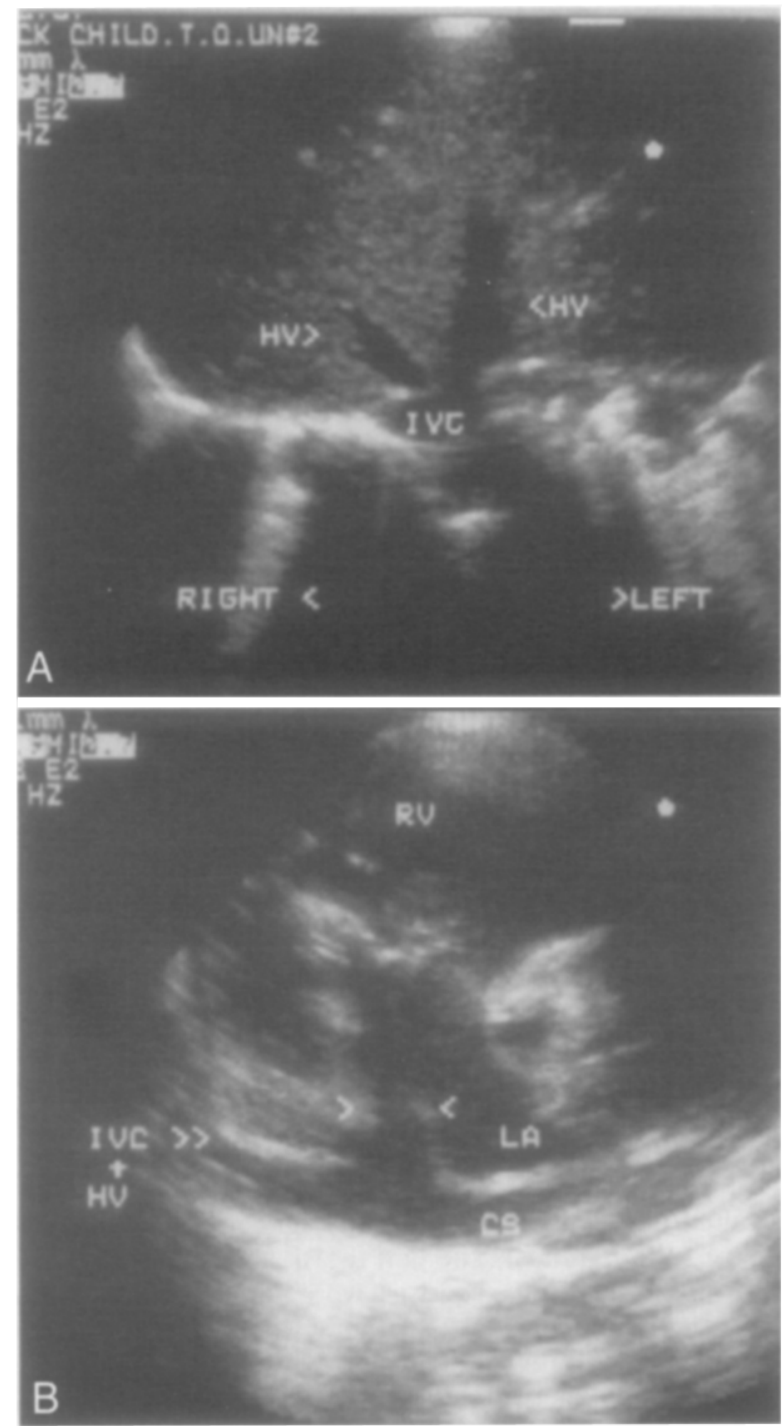

Fig. 2. A, Short-axis view at level of diaphragm. Note all hepatic veins enter IVC. $H V$, Hepatic veins, $L E F T$, left atrium; RIGHT, right atrium. B, Precordial short-axis view demonstrates dilated coronary sinus with IVC and hepatic veins entering it before its termination in right atrium. $\mathrm{RV}$, Right ventricle; $C S$, coronary sinus, $L A$, left atrium, $H V$, hepatic veins.

difficult insertion. The mitral valve was sclerotic and hypoplastic, with an extremely shortened subchordal apparatus emanating from a single papillary muscle. The mitral valve cleft was left unrepaired to avoid iatrogenic mitral stenosis. The ostium primum defect was closed with an autologous pericardial patch, and the ostium secundum defect was closed with a fenestrated patch (one-way valve). The patient had an uneventful recovery and was transferred to the referring center within 9 days.

Discussion. As an isolated lesion, persistence of a left SVC draining into the coronary sinus has been well described, occurring in approximately $0.1 \%$ to $0.5 \%$ of the 
population. ${ }^{3}$ It is usually clinically silent and without consequence. In $9 \%$ to $10 \%$ of the those with a persistent left SVC, such other congenital cardiac anomalies as atrioventricular septal defects, double-outlet right ventricle, cor triatriatum, and mitral atresia have been found, ${ }^{4,5}$ In contrast, absence of the right SVC is much less common, although it has been previously described. ${ }^{6,7}$

Abnormal connections of the IVC are well recognized, especially in combination with visceroatrial heterotaxia. Drainage into the right, middle, and left parts of the common atrium has been well represented in the literature. When the IVC drains into the coronary sinus, the latter structure is almost always unroofed. ${ }^{8}$ Only one previous description of a left-sided IVC draining into the coronary sinus with an intact coronary sinus septum has been published. ${ }^{9}$

During the eighth week of fetal development, the right and left anterior cardinal veins communicate through an oblique anastomosis. Under normal physiologic conditions, this communication shunts blood from the left to the right anterior cardinal vein. The left anterior and left common cardinal veins eventually involute and become the inconstant oblique vein of the left atrium. The transverse portion of the sinus venosus receives this oblique vein and other cardiac veins from the heart walls. It opens into the dorsal wall of the right atrium to become the coronary sinus. ${ }^{10}$ In persons with visceroatrial situs solitus, the upper-torso systemic venous return is thus shifted from a bilateral venous system to a unilateral, right-sided SVC. When the right horn of the sinus venosus becomes incorporated into the morphologically right atrium, it establishes the normal connections of the right SVC and the suprahepatic segment of the IVC with this atrium.

In our patient, the absence of the right SVC probably resulted in a smaller than normal right horn of the sinus venosus. In contrast, the left horn and the transverse portion of the sinus venosus were larger than normal because they received all of the systemic venous return from the upper body. The markedly enlarged coronary sinus formed part of the posterior wall of the morphologically right atrium, and its very large and posteriorly displaced orifice incorporated within its territory the orifice of the IVC.

Development of the atrioventricular valves takes place around the eighth week of fetal development, almost simultaneously with venous formation. Could the abnormal systemic venous return in this patient have given rise to the abnormal structures on the left side of the heart? Abnormal streaming within the right atrium may have diminished adequate preload conditions of the left-sided cardiac chambers of the developing fetus. ${ }^{11-13}$ We are aware of the increased association of malformations involving the left side of the heart in patients with ostium primum defects who have symptoms of congestive heart failure within the first year after birth. ${ }^{2}$ Nevertheless, we strongly suspect that the rare combination of systemic venous anomalies reported here played an additional important role in the maldevelopment of the left-sided structures in this patient.

\section{REFERENCES}

1. Cochrane AD, Marath A, Mee RB. Can a dilated coronary sinus produce left ventricular inflow obstruction? an unrecognized entity. Ann Thorac Surg 1994; 58:1114-6.

2. Manning PB, Mayer JE, Sanders SP, Coleman EA, Jonas RA, Keane JF, et al. Unique features and prognosis of primum ASD presenting in the first year of life. Circulation 1994;90(pt 2):II30-5.

3. Steinberg L, Dubilier W, Lukas D. Persistence of left superior vena cava. Dis Chest 1953;24:479-88.

4. Nsah EN, Moore GW, Hutchins GM. Pathogenesis of persistent left superior vena cava with a coronary sinus connection. Pediatr Pathol 1991;11:261-9.

5. Buirski G, Jordan SC, Joffe HS, Wilde P. Superior vena caval abnormalities: their occurrence rate, associated cardiac abnormalities and angiographic classification in a pediatric population with congenital heart disease. Clin Radiol 1986; 37:131-8.

6. Lenox CC, Zuberbuhler JR, Park SC, Neches WH, Mathews RA, Fricker FJ. Absent right superior vena cava with persistent left superior vena cava: implications and management. Am J Cardiol 1980;45:117-22.

7. Pugliese P, Murzi B, Aliboni M, Eufrate S. Absent right superior vena cava and persistent left superior vena cava: clinical and surgical considerations. J Cardiovasc Surg 1984; 25:134-7.

8. Rubino M, Van Praagh S, Kadoba K, Pessoto R, Van Praagh $R$. Systemic and pulmonary venous connections in visceral heterotaxy with asplenia. J Thorac Cardiovasc Surg 1995;110: 641-50.

9. Van Praagh S, Kreutzer J, Alday L, Van Praagh R. Systemic and pulmonary venous connection in visceral heterotaxy, with emphasis on the diagnosis of the atrial situs: a study of 109 postmortem cases. In: Clark EB, Takao A, editors. Developmental cardiology: morphogenesis and function. Mount Kisco (NY). Futura Publishing, 1990:671-727.

10. Arey LB. Developmental anatomy: a textbook and laboratory manual of embryology. Philadelphia: WB Saunders, 1965: $365,382-3$.

11. Harh JY, Paul MH, Gallen WJ, Friedberg DX, Kaplan S. Experimental production of hypoplastic left heart syndrome in the chick embryo. Am J Cardiol 1983;31:51-6.

12. Weinberg PM, Chin AJ, Murphy JD, Pigott JD, Norwood WI. Postmortem echocardiography and tomographic anatomy of hypoplastic left heart syndrome after palliative surgery. Am J Cardiol 1986;58:1228-32.

13. Lev M, Arcilla R, Rimoldi HJ, Licata RH, Gaul BM. Premature narrowing or closure of the foramen ovale. 1963; 65:638-47. 